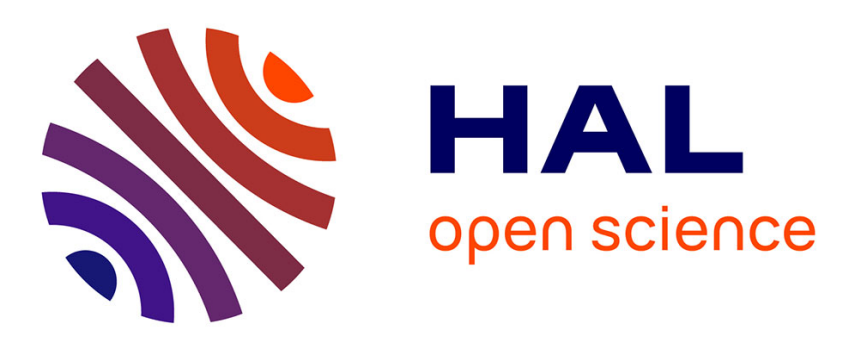

\title{
The $[\mathrm{SiO} 4 / \mathrm{M}]^{\circ}$ centers $(\mathrm{M}=\mathrm{Li}$ or $\mathrm{Na})$ and some physical properties related to these centers in quartz
}

A. Halperin

\section{To cite this version:}

A. Halperin. The $[\mathrm{SiO} 4 / \mathrm{M}]^{\circ}$ centers $(\mathrm{M}=\mathrm{Li}$ or $\mathrm{Na})$ and some physical properties related to these centers in quartz. Journal de Physique IV Proceedings, 1994, 04 (C2), pp.C2-113-C2-121. 10.1051/jp4:1994214 . jpa-00252482

\section{HAL Id: jpa-00252482 https://hal.science/jpa-00252482}

Submitted on 1 Jan 1994

HAL is a multi-disciplinary open access archive for the deposit and dissemination of scientific research documents, whether they are published or not. The documents may come from teaching and research institutions in France or abroad, or from public or private research centers.
L'archive ouverte pluridisciplinaire HAL, est destinée au dépôt et à la diffusion de documents scientifiques de niveau recherche, publiés ou non, émanant des établissements d'enseignement et de recherche français ou étrangers, des laboratoires publics ou privés. 


\title{
The $\left[\mathrm{SiO}_{4} / \mathrm{M}\right]^{\circ}$ centers $(\mathrm{M}=\mathrm{Li}$ or $\mathrm{Na})$ and some physical properties related to these centers in quartz
}

\author{
A. HALPERIN
}

Racah Institute of Physics, The Hebrew University of Jerusalem, Jerusalem 91904, Israel

\begin{abstract}
The observation and explanation of the thermoluminescence (TL) and $\mathrm{x}$-ray induced luminescence (XL) related to $\left[\mathrm{SiO}_{4} / \mathrm{M}\right]^{ \pm}$electron traps in quartz is reviewed. The TL related to these traps appears at about 190 and $200 \mathrm{~K}$ (at heating rate of $10 / \mathrm{min}$ ) in $\mathrm{Li}$ and $\mathrm{Na}$ containing quartz respectively. These TL peaks need generally a double irradiation procedure for their excitation. The review describes and discusses some characteristics of these peaks; e.g. their formation curves, their dependence and preirradiation at various temperatures and their dose dependence. Both the process of formation of the above TL peaks and that of the $\left[\mathrm{SiO}_{4} / \mathrm{M}\right]^{+}$related $\mathrm{XL}$ involve the migration of the $\mathbf{M}^{+}$ions in the quartz lattice and as such their investigation should be of help in the understanding of the dielectric losses and of the radiation induced frequency offsets of quartz resonators known to be affected by the migration of $\mathrm{Li}$ and $\mathrm{Na}$ ions in the quartz lattice.
\end{abstract}

\section{INTRODUCTION}

A surprising effect has been observed in the early eighties in the thermoluminescence (TL) of aluminum containing quartz: a TL peak near 190K or TL(190), which did not appear at all after a conventional single excitation by $\mathrm{x}$-rays, appeared as the strongest TL peak after a suitable double excitation [1,2]. This TL peak was often two orders of magnitude stronger compared to the conventional peaks in the glow curve of quartz. An investigation combining TL and EPR measurements has revealed that the TL(190) was related to $\mathrm{Li}^{+}$ions serving as charge compensators in Al-containing quartz, and more specifically, to $\left[\mathrm{SiO}_{4} / \mathrm{Li}\right]^{\circ}$ centers formed during the double irradiation procedure. An analogous TL peak was observed near $200 \mathrm{~K}$ (TL200) in crystals in which the $\mathrm{Li}$ was replaced by $\mathrm{Na}$ [5]. The formation of these centers was found to involve migration of the monovalent ion $\mathrm{M}(\mathrm{M}=\mathrm{Li}$ or $\mathrm{Na}$ ) away from the $\mathrm{Al}$ impurity centers along the c-axis channels in the quartz lattice. More recent work in our laboratory was concentrated on the characteristics of the TL(190) and TL(200) of $\mathrm{Li}$ and $\mathrm{Na}$ containing quartz respectively and on other properties (e.g. X-ray induced luminescence) related to these ions. The results of these investigations give an insight into the effects related to the migration of the $\mathrm{M}^{+}$ions in the quartz lattice. The migration of these ions is well known to play a significant role in the radiation induced frequency offsets and in the dielectric losses in quartz resonators. The results of the investigations related to the migration of the $M$ ions in quartz should therefore help in our understanding of the frequency shifts and dielectric losses in quartz resonators.

In this presentation we shall give a short review of some of the results of our investigations related to the effects of the $\mathrm{M}^{+}$ions on the physical properties of quartz. 


\subsection{EXPERIMENTAL}

Samples used in the work described below were cut from +x-growth sections of Sawyer synthetic electronic grade quartz. The aluminum content in these samples was $30-50 \mathrm{ppm}$ per silicon atom. The as-received samples contained mainly lithium as charge compensators near the $\mathrm{Al}$. In some of the samples the $\mathrm{Li}$ was replaced by $\mathrm{Na}$ by electric sweeping [5].

Samples $11 \times 8 \times 2 \mathrm{~mm}^{3}$ with the main faces perpendicular to the Y-axis were polished to nearly optical flatness, and were clamped in a bore in the cold finger of a metal liquid nitrogen cryostat provided with Spectrosil fused silica windows for the optical measurements and a thin $(0.3 \mathrm{~mm})$ aluminum window for the $\mathrm{x}$-irradiation. A heater enabled linear heating in the range 80-750K. The emission from the sample was focussed on the photocathode of a photomultiplier (E.M.I. 6256S in most experiments) by a quartz lens. A Corning 1-69 heat absorbing filter in the optical path between the sample and the photomultiplier helped to reduce the black body radiation which was important above $700 \mathrm{~K}$. The output was amplified and recorded on a chart recorder.

Excitation was by $\mathrm{x}$-rays from a tungsten target at $55 \mathrm{Kvp}, 18 \mathrm{ma}$, when the sample received about $2 \mathrm{~Gy} / \mathrm{sec}$.

When not otherwise specified, the TL measurements were performed by heating of the sample at $10 \mathrm{~K} / \mathrm{min}$.

A Jarrell-Ash $0.25 \mathrm{~m}$ grating monochromator was used for the spectral measurements. Suitable optical filters were used in some of the measurements to isolate spectral emission bands.

\subsection{RESULTS}

1.2.1. Conventional TL Peaks and the TL(190) and TL(200) peaks in Quartz.

A schematic diagram of the conventional TL measurements is shown in Figure 1a. In this case the sample is brought (mostly by cooling) to the temperature desired for irradiation. After the irradiation it is warmed up (mostly linearly), when the TL peaks are emitted.

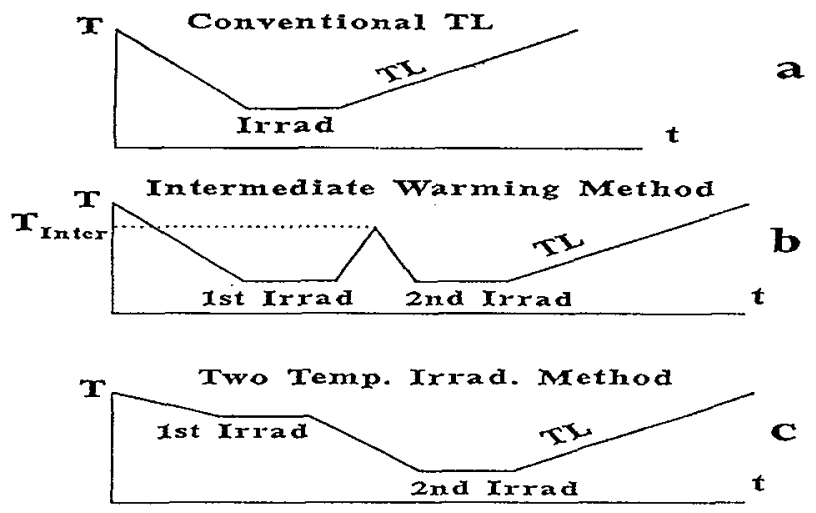

Figure 1. Schematic diagram of the measurement procedures: a. for conventional TL, b. intermediate warming double irradiation method, and c. two temperature irradiation method.

Curves $b$ and $c$ of Figure 1 give two procedures used for the formation of the TL(190) or TL(200) peaks. In $b$ the sample is cooled to the desired excitation temperature, when the first irradiation takes place. It is now just warmed up to a suitable intermediate temperature (near 250K) and cooled back to the low temperature at which the second irradiation takes place. Warming will now show the unconventional TL peak.

This is illustrated in Figure 2. Curve 1 in Figure 2 gives the glow curve obtained by 
procedure a (Figure 1) as obtained after a single $5 \mathrm{~min}$. $\mathrm{x}$-irradiation at $10 \mathrm{~K}$, and Curve 2 gives that obtained by a double $\mathrm{x}$-irradiation of $5 \mathrm{~min}$ each at $10 \mathrm{~K}$ with an intermediate warming to $250 \mathrm{~K}$ betweenthe two irradiations. The effect is striking. The TL(190) peak

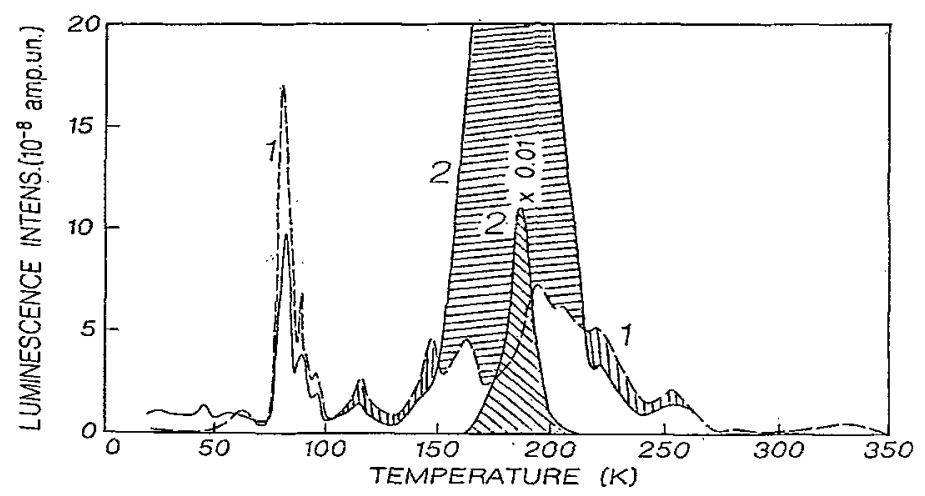

Figure 2. Glow curves for the same quartz sample. Curve 1 - after a single 5 min. $x-$ irradiation at $10 \mathrm{~K}$. Curve 2 - after two $5 \mathrm{~min}$ irradiations at $10 \mathrm{~K}$, and intermediate warming to $250 \mathrm{~K}$.

absent in Curve 1 appears in Curve 2 at an intensity higher by 2 orders of magnitude compared to the conventional TL peaks.

The full explanation of the formation of the unconventional TL peaks was obtained by an investigation of the TL(190) and the EPR carried out on samples cut from adjacent parts of the same quartz crystal and treated similarly throughout the investigation. The investigation has revealed the EPR spectrum of the $\left[\mathrm{SiO}_{4} / \mathrm{Li}\right]^{\circ}$ centers and has disclosed the relation of these centers to the TL(190) peak $[3,4]$.

The processes involved in the formation of the $\left[\mathrm{SiO}_{4} / \mathrm{Li}\right]^{\circ}$ centers and the emission of the TL(190) are summed up below:

1st step - free holes provided during the first low temperature

$\mathrm{x}$-irradiation get captured at the $\mathrm{Al}-\mathrm{Li}$ centers:

$$
\left[\mathrm{AlO}_{4} / \mathrm{Li}\right]^{\circ}+\mathrm{h}^{+}-\cdots\left[\mathrm{AlO}_{4} / \mathrm{M}, \mathrm{h}\right]^{+}
$$

2nd step - warming to the intermediate temperature (e.g. 250K) supplies enough thermal energy for the Li-ions, now only loosely bound to the $\mathrm{Al}$, who leave the $\mathrm{Al}$ and migrate along the $\mathrm{x}$-axis channels to regular $\mathrm{SiO}_{4}$ sites:

$$
\left[\mathrm{AlO}_{4} / \mathrm{M}, \mathrm{h}\right]^{+}------ \text {warming to } 250 \mathrm{~K}------\left[\mathrm{AlO}_{4} / \mathrm{h}\right]^{\circ}+\left[\mathrm{SiO}_{4} / \mathrm{Li}\right]^{+}
$$

3rd step - Free electrons created during the second low temperature $x$-irradiation get captured at the effective $\left[\mathrm{SiO}_{4} / \mathrm{Li}\right]^{+}$electron traps:

$$
\left[\mathrm{SiO}_{4} / \mathrm{Li}\right]^{+}+\mathrm{e}^{-}------\left[\mathrm{SiO}_{4} / \mathrm{Li}\right]^{\circ}
$$

4th step - Warming to $190 \mathrm{~K}$ releases the $\left[\mathrm{SiO}_{4} \mathrm{Li}\right]^{\circ}$ electrons up to the conduction band, when the TL(190) is emitted on recombination with holes at luminescence centers.

The processes involved in the two temperature method for the production of the TL(190) are much the same as those of the intermediate warming method except that the first irradiation taking place now at the intermediate temperature produces an immediate release of the Li-ions (steps 1 and 2 are combined).

The formation of the TL $(200)$ in $\mathrm{Na}$ containing quartz is analogous to that of the TL(190) peak $[5,6,7]$. An illustration of the analogy between the TL(190) and the TL(200) for the two glow curves is shown in figure 3 , where Curve 1 gives the glow curve for a Li- 
containing sample and curve 2 gives that obtained after replacing the $\mathrm{Li}$ by $\mathrm{Na}$. The ordinate scales are the same for both curves, and the intensities are almost equal.

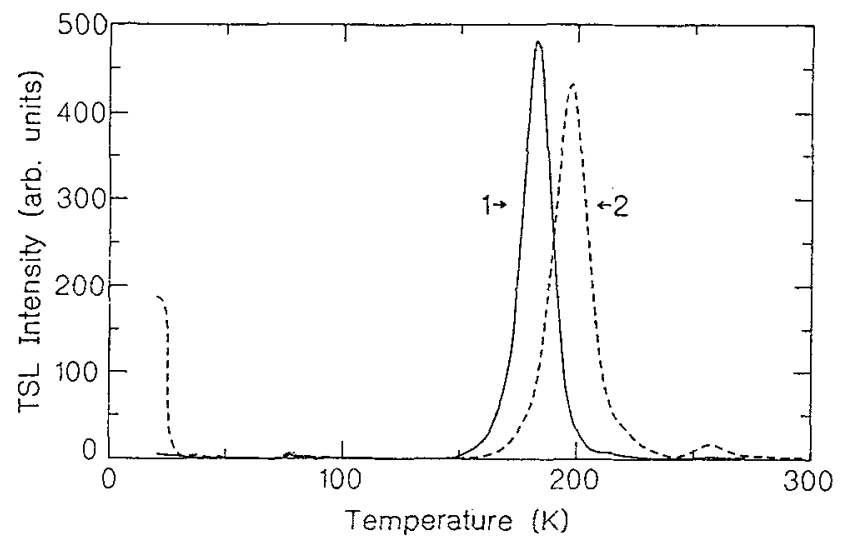

Figure 3. Comparison of the glow curves for: 1. Li-containing and 2. Na-containing, samples as obtained by the "intermediate warming" method of excitation.

Figure 4 gives the formation curves for TL(190) and TL(200). In this figure

Figure 4. Formation curves for the TL(190) and TL(200) peaks as obtained by the intermediate warming method of excitation.

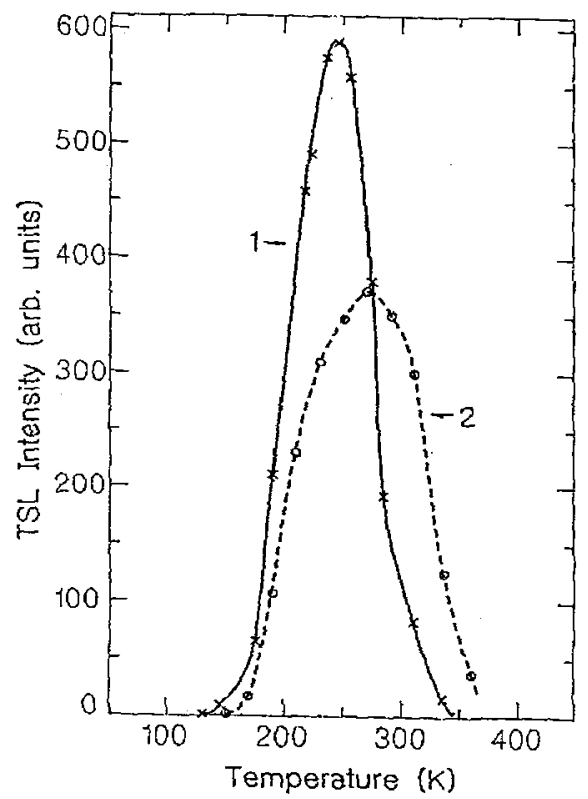

the abscissa gives the temperature reached at the intermediate warming. The curves are similar with the one for the TL(200) shifted to a somewhat higher temperature compared to that of the TL(190) indicating a higher binding of the $\mathrm{Na}^{+}$to the $\mathrm{Al}-\mathrm{h}^{+}$centers compared to that of $\mathrm{Li}^{+}$.

It is worth noting that the TL(190) and TL(200) peaks were found to give the same emission band $(3.25 \mathrm{ev}$, or about $385 \mathrm{~nm})$. This emission was also observed for most of the TL peaks of quartz in the temperature range $110-280 \mathrm{~K}$. $[1,8]$ which implies that all these TL 
peaks are obtained by the release of electrons from traps and their recombination at the same luminescence centers. The identical emission for the TL(190) and TL(200) also indicates that the luminescence centers do not contain either of the two alkali-metal ions.

\subsubsection{Dose Dependence of the TL(190) and Tl(200) Peaks}

The dependence on the irradiation doses of the intensities of the 190 and $200 \mathrm{~K}$ TL peaks is very similalr for the $\mathrm{Li}$ - and $\mathrm{Na}$-containing quartz samples respectively. We shall therefore use the notation TL(M) for both the peaks $(\mathbf{M}=\mathbf{L i}$ or $\mathrm{Na})$. A detailed report is given elsewhere $[9,10]$. Below is given a short description stressing the main features of the dose dependence of TL(M).

During the first $x$-irradiation positive holes get trapped at the $[\mathrm{AlO} / \mathrm{M}]^{0}$ centers. The thus formed $\left[\mathrm{AlO}_{4} / \mathrm{M}\right]^{+}$centers will then release the $\mathrm{M}$ ions on warming to $250 \mathrm{~K}$ (see 1.2.1.). Our observations show that one or two seconds of $x$-irradiation are enough to release most of the available $M$-ions by the above process. One might then expect for a fixed second exposure $\left(t_{2}=\right.$ const.) curves describing the TL(M) intensity as function of the first exposure time $\left(\mathrm{t}_{1}\right)$ to saturate at comparatively low $\mathrm{t}_{1}$ values. This is not the case as shown in Figure 5 , which gives the dependence of TL(190) on $t_{1}$. Curve 1 in this figure rises almost linearly with $t_{1}$ (slope close to 1 on a $\log -\log$ scale), and tends to saturate at $t_{1}$ values close to $10^{3}$ sec. This unexpected rise with $t_{1}$ of the intensity of the $190 \mathrm{~K}$ TL peak lies in the competition for electrons between the $\left[\mathrm{SiO}_{4} / \mathrm{Li}\right]^{+}$traps and other empty electron traps in the crystal during the second $x$-irradiation. This competition acts in favor of the $\left[\mathrm{SiO}_{4} / \mathrm{Li}\right]^{+}$traps when $\mathrm{t}_{1}$ is increased which fills up more and more of the competing traps. This is illustrated in Curves 1-4 of Figure 5, which differ from one another only in the degree of prefilling of the

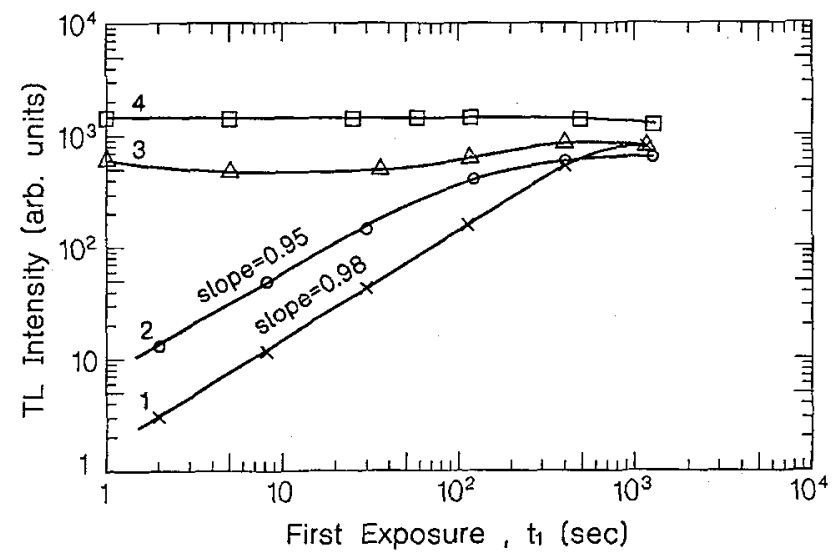

Figure 5. Dependence of TL(190) on $t_{1}$. Curves 1-4, after filling up all traps stable at 700, 400,300 and $250 \mathrm{~K}$ respectively

competing traps. In Curve 1 all traps unstable at $700 \mathrm{~K}$ were empty. Curves $2-4$ were taken after filling up to saturation of the electron traps at 400,300 and $250 \mathrm{~K}$ respectively. It can be seen that at the lowest $t_{1}$ values the $190 \mathrm{~K}$ TL peak rises fast with the prefilling of more and more of the competing traps, and when practically all the competing traps are full (Curves 3 and 4 ) the curves are almost flat (slopes nearly 0 ).

Fig. 6 gives the dependence of the TL(190) on the second irradiation time $\left(t_{2}\right)$ with $t_{1}$ rising from $2 \mathrm{sec}$ in Curve 1 up to $1250 \mathrm{sec}$ in Curve 5. All the curves in Figure 6 rise somewhat superlinearly (slopes $1.10-1.18$ ) at low $t_{2}$ values (up to above $10^{2} \mathrm{sec}$ ). A detailed examination of these slopes shows that part of the rise is due to the increase in $t_{2}$ and part of it results from the filling up of the competing electron traps during the second irradiation which becomes more effective with the increase of $t_{2}$. 


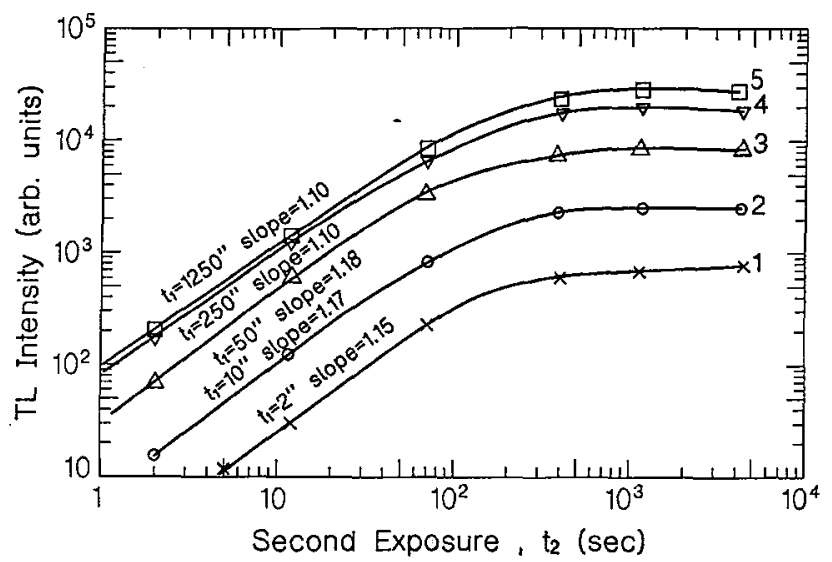

Figure 6. Dependence of TL(190) on $t_{2}$ after long preirradiation at $400 \mathrm{~K}$. Curves 1-5, after first irradiation $\left(\mathrm{t}_{1}\right)$ for $2,10,50,250$ and $1250 \mathrm{sec}$ respectively.

\subsubsection{Release of the $\mathrm{M}^{+}$Ions from the Al Centers}

It is generally claimed that at high enough temperatures, e.g. above $200 \mathrm{~K}$, the alkali ion is able to diffuse away from the $\mathrm{Al}$ site during irradiation [11-13]. While it is correct that under irradiation (at temperatures above $15 \overline{0 \mathrm{~K}}$ ) the $\mathrm{M}^{+}$ions migrate away from the $\mathrm{Al}$, it is clear, from the present results that irradiation at low temperatures followed by warming to above $150 \mathrm{~K}$ releases the $\mathrm{M}^{+}$ions from the $\mathrm{Al}$ sites. As shown above (1.2.1) the low temperature irradiation produces $\left[\mathrm{AlO}_{4} / \mathrm{M}, \mathrm{h}\right]^{+}$centers, when the $\mathrm{M}^{+}$ions become loosely bound to the $\mathrm{Al}$. Warming to above $150 \mathrm{~K}$ then supplies enough thermal energy for the $\mathrm{M}^{+}$ ions to move away. The thermal activation energies needed for the release of the $\mathrm{M}^{+}$ions were found to be 0.25 and $0.31 \mathrm{ev}$ for the $\mathrm{Li}$ and $\mathrm{Na}$ ions respectively [14,15]. One can still ask which of the two methods (irradiation at, let us say, $250 \mathrm{~K}$ or irradiation at very low temperatures followed by warming to $250 \mathrm{~K}$ ), is more effective in the release of the $\mathrm{M}^{+}$ions from the $\mathrm{Al}$ sites. This problem is now under investigation in our laboratory. The intensities of the TL(M) peaks obtained with the same irradiation doses (same $t_{1}$ and $t_{2}$ ) were generally higher when the first $\mathrm{x}$-irradiation was performed at $250 \mathrm{~K}$ (the "Two temperature method"). This is shown in Figure 7 where Curve 1 was obtained by the intermediate warming method and Curve 2 by the two temperature method. In both cases $t_{1}$ was $250 \mathrm{sec}$ and $t_{2} 500 \mathrm{sec}$. The TL(190) in Curve 2 is seen to be more intense ( $x$ 2.3) compared to Curve 1 . Under different conditions of irradiation the intensity ratio of the TL(M) obtained by the two methods was even above 4. Does this higher TL(M) intensity result from a more efficient release of the $\mathrm{M}^{+}$ions from the $\mathrm{Al}$ on irradiation at $250 \mathrm{~K}$ when the trapping of the holes at the $\mathrm{Al}$ centers and the migration of the $\mathrm{M}^{+}$ions takes place simultaneously? Preliminary experiments show that this is not the case. The higher TL(M) intensities obtained by performing the first irradiation at $250 \mathrm{~K}$ seem to be primarily due to a more effective filling of the competing deep electron traps by irradiation at $250 \mathrm{~K}$ compared to that of the irradiation at the lower temperatures. This is shown in Figure 8, which gives the TL(190) intensity as function of the second exposure $\left(t_{2}\right)$. In this figure the $x$-s give the TL(190) obtained by the intermediate warming method (first irradiation at $80 \mathrm{~K}$, followed by warming to $250 \mathrm{~K}$ ) and the $o-s$ give that obtained by first irradiation at $250 \mathrm{~K}$. In both cases $t_{1}$ was 100 sec. The measurements started after pre-warming to about $750 \mathrm{~K}$, thus emptying alf the traps unstable at $750 \mathrm{~K}$. The numbers at the points in the figure give the chronological order of the measurements. All the points now lie almost on the same curve. Point 12 in the figure was obtained at the end of the series of measurements after rewarming to $750 \mathrm{~K}$, and fits well on 
the curve. We conclude from these results that the efficiency of the release of the $\mathrm{M}^{+}$ions from the Al sites by irradiation at very low temperatures followed by warming to $250 \mathrm{~K}$ is practically the same as that obtained by irradiation at $250 \mathrm{~K}$.

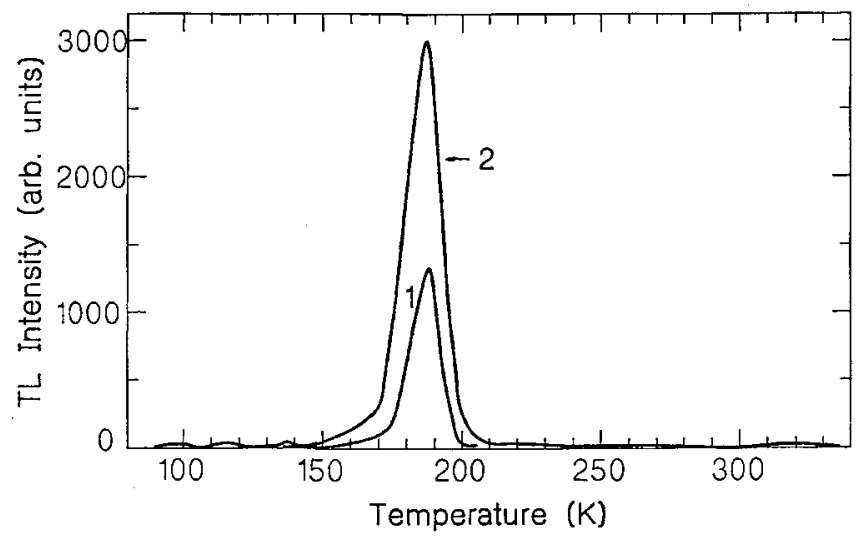

Figure 7. Glow curves obtained by : 1 - first $\mathrm{x}$-irradiation at $80 \mathrm{~K}$ followed by warming to $250 \mathrm{~K}$, and 2 - first $\mathrm{x}$-irradiation at $250 \mathrm{~K}$. In both cases the first exposure time was 250 secs. and the second was at $80 \mathrm{~K}$ for $500 \mathrm{sec}$.

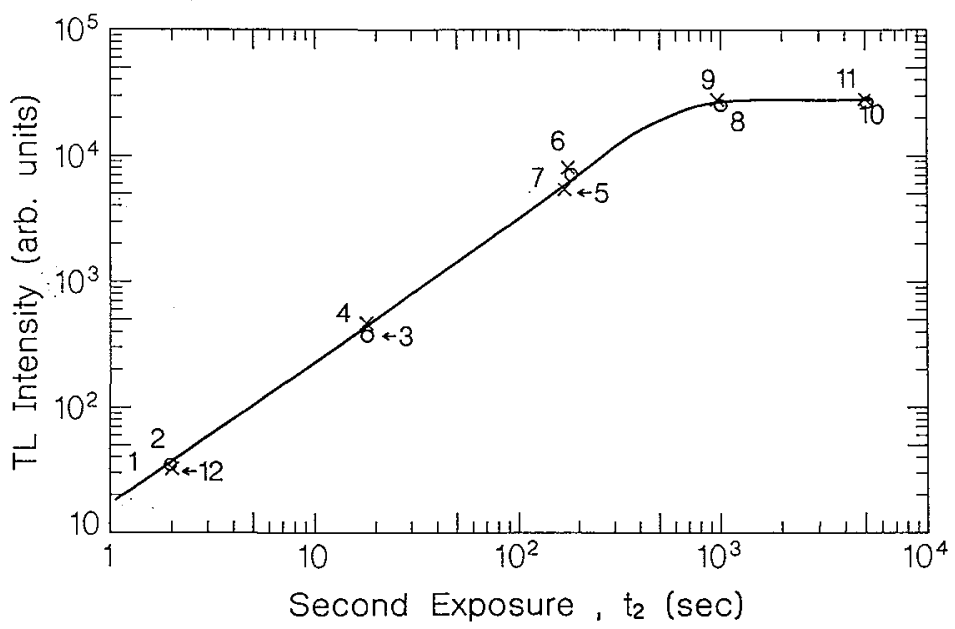

Figure 8. TL(190) intensities as obtained by: $\mathrm{x}$ - first irradiation for 100 sec at $80 \mathrm{~K}$ followed by warming to $250 \mathrm{~K}$, and $\mathrm{o}$ - by first irradiation $(100 \mathrm{sec})$ at $250 \mathrm{~K}$. The numbers at the experimental points give the chronological order of the measurements. Crystal was heated to $750 \mathrm{~K}$ before starting the measurements and again before measurement 12 .

1.2.4. Temperature Dependence of the 3.2ev X-Ray Induced Luminescence(XL).

The XL of the samples used in our measurements showed emission bands at about 2.4, 2.8 and $3.2 \mathrm{cv}$. Some results on the temerature dependence of these bands were reported earlier [16,18]. The present discussion concentrates on the $3.2 \mathrm{ev}$ band which was found to be related to the $\mathrm{M}^{+}$ions.

In general, the $\mathrm{XI}$ of the quartz samples used in this investigation exhibited drops in the XL intensities at four temperature ranges. For Li containing quartz these drops occurred at $120-160,170-220,220-270$ and $380-454 \mathrm{~K}$ (Stages I to IV respectively). With $\mathrm{Na}$ replacing the Li Stage III and especially Stage IV, appeared at somewhat higher temperatures. The $\mathrm{XL}$ measurements started after preheating of the sample to $750 \mathrm{~K}$, thus emptying all electron 


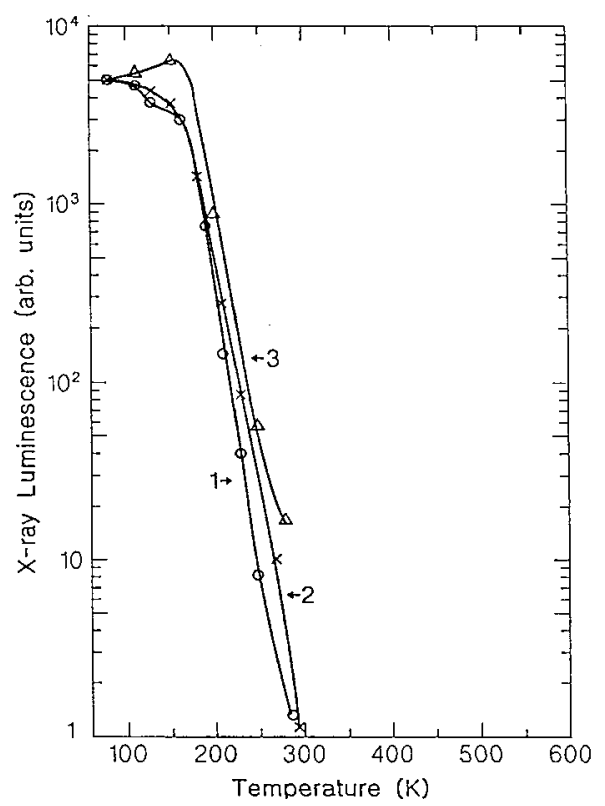

Figure 9. Temperature dependence of the XL of a sample annealed at $750 \mathrm{~K}$. 1 $2.4 \mathrm{ev}, 2-2.8 \mathrm{ev}$ and $3-3.2 \mathrm{ev}$ emissions. Curves normalized at $80 \mathrm{~K}$. Exposures at each measuring point $1 \mathrm{sec}$.

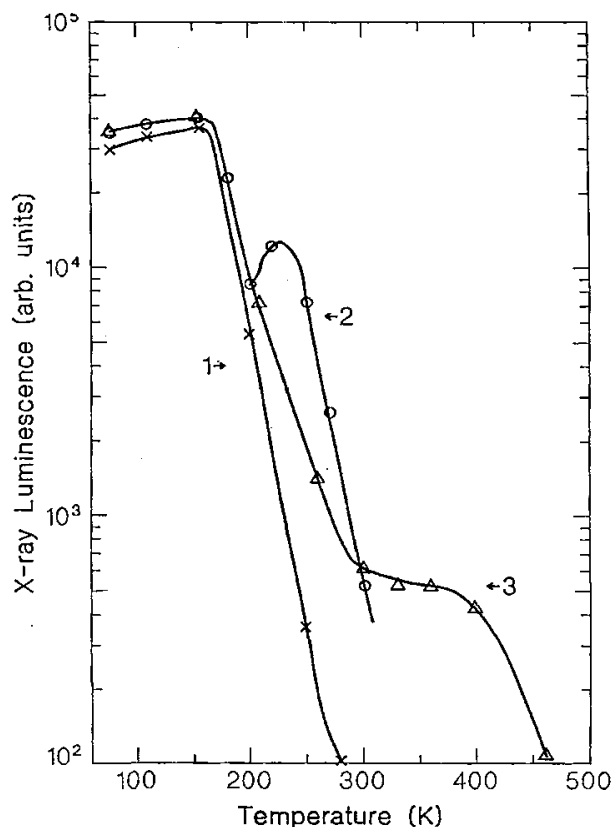

Figure 10. Temperature dependence of the 3.2ev XL. 1 - sample annealed at $750 \mathrm{~K}, 2$ - after $30 \mathrm{~min}$ of preirradiation at $270 \mathrm{~K}$, and 3 - after 1 hour of preirradiation at 410K. Exposure at each measuring point 1 sec.

traps unstable at this temperature. In addition, all exposures to $\mathrm{x}$-irradiation were limited to $1 \mathrm{sec}$, which kept the filling up of the electron traps during a set of measurements for each temperature dependence curve almost negligibly low.

Under these conditions the XL emission bands exhibited only Stages I and II as shown in Figure 9. Curves 1 and 2 in this figure give the temperature dependence of the XL of the 2.4 and $2.8 \mathrm{ev}$ bands respectively. Both show a small drop at Stage I and complete temperature quenching at Stage II. The $3.2 \mathrm{ev} \mathrm{XL}$ (Curve 3) rises slightly in the range of Stage I and drops strongly at Stage II. The curves in Figure 9 were normalized at 80K.

Prolonged preirradiations at various temperatures did not change the behavior of the 2.4 and 2.8 XL bands, which remained limited to Stages I and II. This was not the case for the $3.2 \mathrm{ev} \mathrm{XL}$ as shown in Figure 10 . Curve 1 in this figure was obtained without preirradiation and is practically identical with Curve 3 in Figure 9. Curve 2 was obtained after 30 minutes of preirradiation at $270 \mathrm{~K}$. It shows a strong Stage III emission. For Curve 3 the sample was preirradiated for 1 hour at $410 \mathrm{~K}$. Stage III is now missing and Stage IV appears.

A similar behavior was observed for $\mathrm{Na}$ containing samples. In this case Stage III shifted by about 15 degrees and Stage IV by about 30 degrees, both to higher temperatures compared to those with $\mathrm{Li}$.

The formation curves for Stages III and IV give the $3.2 \mathrm{cv}$ XL intensities at these stages as function of the temperature at which the preirradiation took place. The formation curve for Stage III XL for $\mathrm{Li}$ and $\mathrm{Na}$ containing samples were found to fit closely the formation curves for TL(190) and TL(200 respectively [17]. This points to an involvement of the $\mathrm{M}^{+}$ions in the production the Stage III and Stage IV $3.2 \mathrm{eV}$ XL. The common emission band $(3.2 \mathrm{eV})$ in the $\mathrm{XL}$ and $\mathrm{TL}(\mathrm{M})$ also indicates that recombination takes place at the same luminescence center in both cases.

The formation of the Stage III XL can be explained as follows: Preirradiation at temperatures below $150 \mathrm{~K}$ removes very little, if at all, of the $\mathrm{M}^{+}$ions from the $\mathrm{Al}$ centers. At higher temperatures more and more $\mathrm{M}^{+}$ions are removed and form $\left[\mathrm{SiO} / \mathrm{M}^{+}\right.$electron traps (1.2.1. above). The removal of $\mathrm{M}^{+}$ions at temperatures above $150 \mathrm{~K}$ leaves behind 
$\left[\mathrm{AlO}_{4} \mathrm{~h}^{+}\right]^{\circ}$ centers which are assumed to act as luminescence centers for the $3.2 \mathrm{eV}$ emission. To this point the process is exactly the same for the TL(M) and the $3.2 \mathrm{eV}$ XL. Now the short $(1 \mathrm{sec})$ probe irradiations provides free electrons (and holes) when the XL luminescence will rise with the concentration of the $\left[\mathrm{AlO}_{4} / \mathrm{h}^{+}\right]^{\circ}$ luminescence centers and will qualitatively fit the TL(M) formation curve. Quantitatively, one has to take in account competition for the electrons between the luminescence centers and the efficient $\left[\mathrm{SiO}_{4} / \mathrm{M}\right]^{+}$electron traps. This is however beyond the scope of the present paper.

The Stage IV formation curves for $\mathrm{Li}$ and $\mathrm{Na}$ containing samples peak at about 350 and close to $400 \mathrm{~K}$ respectively. It has been suggested $[16,17,18]$ that at temperatures above $300 \mathrm{~K} \mathrm{M}^{+}$ions released from the Al sites become captured at unidentified defects $X$ to form $[\mathrm{X} / \mathrm{M}]^{+}$electron traps analogous to the $\left[\mathrm{SiO}_{4} / \mathrm{M}\right]^{+}$traps. So the support to this hypothesis was provided by a TL peak at $180 \mathrm{~K}$, which replaces the TL(190) under certain conditions of preirradiation [18]. This TL peaks gives a formation curve fitting that of the Stage IV TL.

\section{REFERENCES}

[1] Malik D.M., Kohnke E.E. and Sibley W.A., J. Appll Phys. $\underline{52}$ (1981) 3600.

2. Halperin A. and Katz S., J. Luminescence 31 (1984) 129.

3 Jani M.G., Halliburton L.E. and Halperin A., Phys. Rev. Letters 56 (1986) 1392.

4 Halperin A., Jani M.G. and Halliburton L.E., Phys. Rev. 343 (1986) 5702.

5 Halperin A. and Katz S., Solid State Commun. 63 (1987) 697.

6 Halperin A. and Katz S., J. Luminescence 40-41 (1988) 341.

7. Halperin A. and Katz S., Proc. 42nd Freq. Control Symposium (1988) 185.

8 Katz S. and Halperin A., J. Luminescence 39 (1988) 127.

9. Halperin A. and Sucov E.W. ,J. Phys. Chem. Solids 54(1993) 431.

10] Halperin A., Proc. 47th Freq. Control Symposium (1993). In press.

11) McKeever S.W.S., Radiation Protection Dosimetry $\underline{8}$ (1984) 86.

12] Halliburton L.E., Koumvakalis N., Markes M.E. and Martin J.J., J. Appl. Phys. $\underline{52}$ (1981) 3572.

[13] Martin J.J., J. Appl. Phys. 56 (1984) 2536.

14 Halperin A., J. Phys. Chem. Solids 51 (1990) 303.

15 Halperin A. and Sucov E.W., J. Phys. Chem. Solids $\underline{52}$ (1991) 1039.

16 Halperin A., J. Luminescence 48-49(1991) 606.

17. Halperin A., J. Phys. Chem. Solids 54 (1993) 43.

18] Halperin A. and Katz S., J. Phys. Chem. Solids 49 (1988) 577. 